\title{
EFEITO DO CORTE COMO DANO MECÂNICO NA QUALIDADE E NA FISIOLOGIA DE MAMÕES 'GOLDEN’’
}

\author{
JAQUELINE VISIONI TEZOTTO², ANGELO PEDRO JACOMINO ${ }^{3}$, ANA ELISA DE GODOY 4 , \\ ELAINE COSTA CERQUEIRA-PEREIRA ${ }^{5}$, CAMILLA ZANOTTI GALLON ${ }^{6}$
}

\begin{abstract}
RESUMO - A redução na qualidade pós-colheita do mamão deve-se em grande parte aos danos mecânicos, especialmente àqueles do tipo corte. O objetivo deste trabalho foi reproduzir este dano mecânico e avaliar os efeitos do número de cortes na qualidade e na fisiologia pós-colheita de mamões 'Golden'. Os cortes foram obtidos com o uso de uma lâmina de aço de $30 \mathrm{~mm}$ de comprimento e $5 \mathrm{~mm}$ de profundidade. Os tratamentos consistiram na reprodução de 1 a 4 cortes na região mediana dos frutos. Mamões sem cortes foram utilizados como controle. Após a reprodução dos danos, os frutos foram armazenados em câmara a $22^{\circ} \mathrm{C}$ e $80-90 \%$ de UR por 10 dias. As análises de qualidade foram realizadas a cada dois dias, e as fisiológicas, diariamente. Os resultados demonstraram que a firmeza, o teor de sólidos solúveis e de ácido ascórbico, a atividade respiratória e a produção de etileno foram influenciados pelo número de cortes, de forma que a perda de qualidade dos frutos foi diretamente proporcional ao número de cortes.
\end{abstract}

Termos para indexação: Carica papaya L., dano mecânico, características físicas e químicas, fisiologia pós-colheita.

\section{EFFECT OF CUTTINGS AS A MECHANICAL DAMAGE ON THE QUALITY AND PHYSIOLOGY OF 'GOLDEN’ PAPAYA FRUIT}

\begin{abstract}
The reduction in postharvest quality of papaya fruit is mainly due to mechanical damage, especially those caused by cuts on the surface. In this study the cuts were reproduced in the laboratory to evaluate the effects of the number of cuts on quality and postharvest physiology of 'Golden' papaya fruit. The cuts were made using a steel blade $30 \mathrm{~mm}$ long and $5 \mathrm{~mm}$ deep. The treatments consisted of making 1 to 4 cuts on the equatorial region of the fruits. Papaya fruits with no cuts were used as control. Fruits were stored at $22^{\circ} \mathrm{C}$ and $80-90 \% \mathrm{RH}$ for 10 days. The quality analyses were performed every two days, whereas the physiological analyses were performed daily. It was observed that firmness, soluble solid content, ascorbic acid content, respiration rate and ethylene production were affected by the number of cuts, showing that the fruit quality loss was directly proportional to the number of cuts.
\end{abstract}

Index terms: Carica papaya L., mechanical damage, physicochemical quality, postharvest physiology.

\section{INTRODUÇÃO}

O mamão ‘Golden’ é um fruto tropical muito apreciado e de grande importância econômica para o Brasil, que vem sendo classificado como o país de maior produção mundial e o terceiro maior exportador (FAO, 2010). Os frutos dessa variedade apresentam polpa com boa durabilidade (MARIN et al., 1989), no entanto exigem muitos cuidados durante as etapas de colheita e pós-colheita, pois possuem casca fina, polpa tenra e apresentam padrão respiratório climatérico (PAULL, 1993), o que acelera o processo de senescência quando essas etapas não são adequadamente conduzidas.

Dessa forma, o mamão está sujeito a perdas pós-colheita por danos mecânicos, patogênicos e fatores abióticos. Esses três fatores podem manifestar-se nos frutos isoladamente ou em conjunto, proporcionando perdas quantitativas, qualitativas e nutricionais em todas as fases da cadeia pós-colheita

\footnotetext{
${ }^{1}$ Trabalho Sinfruit 031 - Simpósio Internacional de Fruticultura - Avanços na Fruticultura (17 a 21 Outubro)

${ }^{2}$ Eng. Agr ${ }^{\circ}$, Mestranda em Fitotecnia na Escola Superior de Agricultura "Luiz de Queiroz" (ESALQ)/Universidade de São Paulo (USP); Av. Pádua Dias nº11, CP. 9, CEP 13418-900, Piracicaba - SP. E-mail: jaqueline.tezotto@usp.br

${ }^{3} \mathrm{Eng}^{\circ}$. Agr ${ }^{\circ}$, Prof ${ }^{\circ}$ Dr. Laboratório de Pós-Colheita de Frutas e Hortaliças, Dep. Produção Vegetal, ESALQ/USP.

E-mail: jacomino@esalq.usp.br

${ }^{4}$ Eng. Agr ${ }^{\circ}$, Doutoranda em Fitotecnia, USP/ESALQ. E-mail: aelisagodoy@yahoo.com.br

${ }^{5}$ Eng. Agr ${ }^{0}$, Dr. em Fitotecnia. E-mail: eccerque@esalq.usp.br

${ }^{6}$ Bióloga, Dr. em Fisiologia e Bioquímica de plantas. E-mail: millazg@gmail.com
} 


\section{(BALBINO, 2003).}

Danos mecânicos podem ser definidos como deformações plásticas, rupturas superficiais e destruição dos tecidos vegetais que, provocados por forças externas, causam modificações físicas, fisiológicas, químicas e bioquímicas, resultando em alterações na cor, aroma, sabor, textura (MOHSENIN, 1986), aumento da atividade respiratória e da produção de etileno. No mamão, os principais danos mecânicos são abrasão, impacto, corte e compressão (GODOY et al., 2010; MORETTI, 2002).

Em trabalho realizado por GODOY et al. (2010), foi constatado que o corte representa aproximadamente 20 \% dos danos mecânicos mais encontrados no mamão. O dano de corte é geralmente atribuído à força de colisão de um fruto em uma superfície irregular, ou pela imposição de uma pressão sobre o fruto, contra uma superfície desigual, como arestas de embalagens de colheita, transporte e armazenamento, ocasionando a ruptura da epiderme (MOHSENIN, 1986).

A quantificação desse dano tem como principal função facilitar a tomada de decisão por parte do produtor, atacadista e varejista quanto à necessidade de investimentos em medidas de prevenção, pois esse estudo possibilita a adoção de medidas para a redução de perdas pós-colheitas que, consequentemente, serão medidas lucrativas. Como o dano mecânico, em especial o corte, é um dos principais motivos para a redução na qualidade e na vida pós-colheita do mamão, o objetivo deste trabalho foi avaliar o efeito do número de cortes na qualidade física e química e na fisiologia pós-colheita de mamões 'Golden'.

\section{MATERIAL E MÉTODOS}

Foram utilizados mamões 'Golden', obtidos de pomar comercial do município de Linhares-ES. Os frutos foram colhidos no estádio 1 de maturação (máximo 15\% da superfície da casca amarela), transportados em caminhão refrigerado a $10^{\circ} \mathrm{C}$ até a CEASA-Campinas-SP e de carro para o laboratório de Pós-Colheita de Produtos Hortícolas da ESALQ-USP, em Piracicaba-SP. Os frutos foram selecionados quanto à ausência de defeitos e danos mecânicos e, posteriormente, submetidos ao dano mecânico do tipo corte.

Os cortes foram realizados com uma lâmina de aço de $30 \mathrm{~mm}$ de comprimento, $1 \mathrm{~mm}$ de espessura e $5 \mathrm{~mm}$ de altura fixada na face superior de um suporte de madeira, que era apoiada sobre o mamão (Adaptado de GODOY et al., 2010). Os frutos foram colocados sobre espumas no orifício central da parte inferior do suporte de madeira, de modo que a região mediana do lado oposto àquele em contato com a espuma ficasse em contato com a lâmina de corte. Para a realização do corte, a parte superior do suporte foi pressionada por um penetrômetro digital até atingir força no intervalo de 95 a $115 \mathrm{~N}$, pois, em testes preliminares, chegou-se ao resultado de que essa força reproduziu o corte de modo mais parecido com o que ocorre na realidade.

O experimento foi constituído por cinco tratamentos de oito repetições, sendo um fruto por repetição. Os tratamentos foram: (i) frutos com ausência do dano de corte, (ii) frutos que receberam corte em apenas um dos lados, (iii) frutos com cortes em dois lados opostos, (iv) frutos com cortes em três lados equidistantes e (v) frutos com cortes nos quatro lados equidistantes.

Após a reprodução do dano mecânico, os frutos foram mantidos em câmara a $22^{\circ} \mathrm{C}$ e $80-90 \%$ de UR. O armazenamento foi por um período de sete dias para os frutos utilizados para as análises fisiológicas, pois após este período constatou-se a presença de podridão e por dez dias para os frutos das análises físicas e químicas.

As análises físicas e químicas foram realizadas no dia da chegada dos frutos, visando à caracterização do lote, e a cada dois dias, durante o armazenamento. As variáveis analisadas foram: firmezas externa (casca) e interna (polpa), determinadas através de penetrômetro digital (marca 53200-Samar, TrTuroni, Forli, Itália)) com ponteira de $8 \mathrm{~mm}$, cujos dados foram expressos em Newton; teor de sólidos solúveis (SS), determinado com refratômetro digital (marca Atago - Palete 101) cujos resultados foram expressos em ${ }^{\circ}$ Brix; acidez titulável (AT), expressa em \% de ácido cítrico por $100 \mathrm{~g}$ de polpa e teor de ácido ascórbico, expresso em mg de ácido ascórbico por $100 \mathrm{~g}$ de polpa, ambos determinados de acordo com a metodologia descrita por Carvalho et al. (1990).

As análises fisiológicas realizadas foram atividade respiratória e produção de etileno. O tempo para tomada das leituras em ambas as variáveis foram: uma hora antes de causar o dano; uma; quatro; oito e 12 horas após o dano ter sido causado, seguindo-se por análises diárias do segundo ao sétimo dia após a reprodução do dano. Frutos foram colocados em recipientes herméticos de vidro, com capacidade de 1,7 L, com tampas contendo septos de silicone. Após uma hora fechados, amostras de $1 \mathrm{~mL}$ de ar do interior dos frascos foram coletadas e injetadas em cromatógrafo a gás, marca Thermo Finnigan, modelo Trace 2000GC, equipado com dois detectores de ionização de chama (FID) regulados para $250^{\circ} \mathrm{C}$, dois injetores regulados para $100^{\circ} \mathrm{C}$, duas colunas 
Porapack N (coluna $\mathrm{CO}_{2}-4 \mathrm{~m}$; coluna $\mathrm{C}_{2} \mathrm{H}_{4}-1,8$ $\mathrm{m})$ reguladas para $100^{\circ} \mathrm{C}$ e um metanador, somente para $\mathrm{CO}_{2}$, regulado para $350^{\circ} \mathrm{C}$. As variáveis foram calculadas, levando-se em consideração o volume do frasco, a massa do fruto e o tempo que os frascos permaneceram fechados. Os resultados foram expressos em $\mathrm{CO}_{2}\left(\mathrm{~mL} \mathrm{~kg}^{-1} \mathrm{~h}^{-1}\right)$ e $\mathrm{C}_{2} \mathrm{H}_{4}\left(\mu \mathrm{L} \mathrm{kg}^{-1} \mathrm{~h}^{-1}\right)$, respectivamente.

O delineamento experimental adotado para todas as variáveis foi inteiramente casualizado, em esquema fatorial composto por dois fatores: número de cortes e dias de armazenamento após a reprodução do dano. Os resultados foram submetidos a análises de variância, e as médias, comparadas pelo teste de Tukey $(\mathrm{P}<0,05)$.

\section{RESULTADOS E DISCUSSÃO}

O número de cortes influenciou sobre a firmeza externa dos mamões 'Golden' (Figura 1a). Os frutos sem danos mecânicos foram mais firmes que os demais, do segundo até o sexto dia de armazenamento. Para os frutos que sofreram 1; 2;3 e 4 cortes, observou-se que até o quarto dia de armazenamento a firmeza externa foi inversamente proporcional ao número de cortes, embora apenas frutos com 1 e 4 cortes diferiram estatisticamente. Jaensch (1996) explica que danos mecânicos causam a perda de firmeza devido à ruptura celular e à atividade enzimática. Possivelmente, o corte causou a ruptura celular, que resultou no colapso da membrana e desencadeou reações, como o aumento da produção de etileno, as quais causaram ou promoveram o amolecimento. Do sexto ao último dia de armazenamento, os frutos de todos os tratamentos atingiram valores de firmeza externa muito próximos.

A firmeza interna também diminuiu em função do número de cortes (Figura 1b). A partir do quarto dia, a firmeza interna da polpa atingiu valores muito baixos, menores do que $5 \mathrm{~N}$, permanecendo constantes até o décimo dia. O amaciamento da polpa proporcionado por danos mecânicos é uma das principais consequências negativas nos atributos da qualidade pós-colheita e também foi observado em mamão cultivar Improved Sunrise Solo (BRAGA, 2004) e pêssego (KASAT et al., 2007).

Não houve diferença no teor de sólidos solúveis ao longo do amadurecimento, no entanto observou-se diferença entre frutos com 3 e 4 cortes no $10^{\circ}$ dia de armazenamento, os quais apresentaram teores de sólidos solúveis em média 1,25 e 1,13 vez menor que os demais tratamentos (Tabela 1). Este resultado pode estar relacionado às maiores taxas respiratórias observadas nos frutos com 3 e 4 cortes
(Figura 1c); possivelmente, os sólidos solúveis serviram de substrato para respiração, apresentando, dessa forma, valores inferiores aos demais tratamentos. Resultados semelhantes foram encontrados por Giannoni et al. (1996) e Mattiuz e Durigan (2001) ao estudarem a influência do corte em pêssego e goiaba, respectivamente.

O número de cortes e o período de armazenamento não interferiram no teor de acidez dos frutos (Tabela 1). Durigan et al. (2005) e Moretti et al. (1998) verificaram diminuição da acidez titulável ao estudarem a influência de danos mecânicos em lima-ácida 'Tahiti' e tomate, respectivamente. Esses autores sugeriram que os ácidos serviram como substratos ao processo respiratório, o que também pode ter ocorrido no presente trabalho, dado que houve aumento na atividade respiratória após a reprodução dos cortes (Figura 1c). Contudo, o aumento da acidez, em função da ocorrência de danos mecânicos, foi observado em abobrinhas (DURIGAN; MATTIUZ, 2007). Os autores relacionaram o aumento da acidez com a presença de $\mathrm{CO}_{2}$ intracelular resultante do ciclo de Krebs. Provavelmente, o comportamento do mamão 'Golden', quanto ao teor de acidez, observado neste trabalho, deve-se a um equilíbrio entre o consumo dos ácidos tituláveis e o aumento da concentração de $\mathrm{CO}_{2}$ intracelular, não sendo possível relacionar a influência do corte sobre a acidez do mamão.

O teor de ácido ascórbico foi influenciado pelo número de cortes e pelo período de armazenamento (Tabela 1). Em todos os tratamentos, observou-se decréscimo do teor do ácido no segundo dia de armazenamento; no entanto, frutos-controle, com 1 e 2 cortes, apresentaram aumento do teor de ácido ascórbico nos últimos dias de armazenamento. Esse aumento está de acordo como observado na literatura para mamão, de forma que o aumento no teor de ácido ascórbico visa à proteção do fruto contra danos oxidativos do metabolismo aeróbio (SMIRNOFF, 1996). Sugere-se que a produção de precursores do ácido ascórbico possa ocorrer devido à degradação de polissacarídeos da parede celular (SMIRNOFF, 2001; GODOY et al., 2010). Frutos com 3 e 4 cortes permaneceram com valores inferiores ao do dia da caracterização (Tabela 1). Também se observou que, após o sexto dia de armazenamento, frutos com 3 e 4 cortes apresentaram teor de ácido ascórbico menor que os demais tratamentos. Provavelmente, isso ocorreu porque esses frutos apresentaram maiores danos oxidativos, cuja ação antioxidante foi fornecida, especialmente, pelo ascorbato, derivado do ácido ascórbico (BARATA-SOARES et al., 2004).

Houve aumento na atividade respiratória e na produção de etileno, sendo maiores os seus valores, 
quanto maior o número de cortes (Figura $1 \mathrm{c} / \mathrm{d}$ ). Os tratamentos apresentaram diferença na atividade respiratória, nas primeiras 12 horas após a reprodução do dano, de modo que frutos sem dano mecânico diferiram dos demais. Frutos com 1 e 2 cortes apresentaram aumento, em média, de 1,6 vez a taxa respiratória em relação aos frutos-controle. Frutos com 3 e 4 cortes também apresentaram o mesmo comportamento e indicaram aumento médio de 1,9 vez em relação ao controle. A partir do segundo dia de armazenamento, a atividade respiratória foi baixa $\left(<10 \mathrm{~mL} \mathrm{~kg}^{-1} \mathrm{~h}^{-1}\right)$ para todos os tratamentos e não houve diferença entre eles. Esse comportamento pode ser atribuído ao estresse provocado pelo corte, o que pode ter ocasionado descompartimentalização celular que, consequentemente, liberou substratos do metabolismo respiratório para os complexos enzimáticos (PURVIS, 1997).

Resultado semelhante foi encontrado por Mattiuz e Durigan (2001) em goiabas. Esses autores justificaram o aumento da atividade respiratória devido ao maior rompimento de células por ocasião do corte, o que teria disponibilizado os ácidos presentes no vacúolo para o sistema respiratório, na tentativa de reparar o dano mecânico. Segundo Kays (1991), esse aumento da respiração em resposta ao ferimento está relacionado ao processo de reparo do dano.

Foi observado que os mamões sem dano mecânico aumentaram a produção de etileno somente a partir do terceiro dia de armazenamento. No entanto, frutos que receberam o dano aumentaram a produção do hormônio nas primeiras horas após a sua reprodução, atingindo um pico 8 horas após o corte ter sido causado. $\mathrm{O}$ aumento da produção de etileno foi, em média, 18,7;16,9; 19,6; e 23,0 vezes em relação ao controle para os frutos com 1;2; 3 e 4 cortes, respectivamente. Segundo Paull e Chen (1983), a concentração do ácido aminociclopropano (ACC), precursor imediato do etileno, aumenta durante o amadurecimento, contudo a presença de maior número de danos mecânicos estimula a ação da enzima ACC sintase, que é a responsável pela conversão da S-adenosilmetionina (SAM) em ACC, fato que pode ter sido o responsável pelo aumento da produção do hormônio nos mamões danificados.

TABELA 1 - Características químicas de mamões 'Golden' submetidos ao dano mecânico do tipo corte e armazenados a $22^{\circ} \mathrm{C}$ e $85 \pm 5 \%$ UR por 10 dias.

\begin{tabular}{|c|c|c|c|c|c|c|c|}
\hline \multirow{2}{*}{\multicolumn{2}{|c|}{$\begin{array}{l}\text { Número de } \\
\text { cortes }\end{array}$}} & \multicolumn{5}{|c|}{ Dias de armazenamento } & \multirow[b]{2}{*}{10} \\
\hline & & $\mathbf{0}$ & 2 & 4 & 6 & 8 & \\
\hline \multirow{6}{*}{ 总总氮 } & Zero & $10,5 \mathrm{Aa}$ & $10,5 \mathrm{Ba}$ & $10,8 \mathrm{Aa}$ & 10,2 Аа & 11,3 Аa & $11,5 \mathrm{Ba}$ \\
\hline & Um & 10,5 Aab & 11,0 Bab & 10,5 Aab & 9,8 Аа & 10,3 Aab & $11,7 \mathrm{Bb}$ \\
\hline & Dois & $10,5 \mathrm{Aab}$ & $9,2 \mathrm{Aa}$ & 10,8 Aab & 10,7 Aab & $11,3 \mathrm{Ab}$ & $11,3 \mathrm{Bb}$ \\
\hline & Três & $10,5 \mathrm{Ab}$ & 9,8 ABab & $10,8 \mathrm{Ab}$ & $10,2 \mathrm{Ab}$ & $10,3 \mathrm{Ab}$ & $9,2 \mathrm{Aa}$ \\
\hline & Quatro & $10,5 \mathrm{Aa}$ & $11,3 \mathrm{Ba}$ & $10,5 \mathrm{Aa}$ & 10,3 Аa & $10,8 \mathrm{Aa}$ & $10,2 \mathrm{Aa}$ \\
\hline & DMS & 1,1 & & & & & \\
\hline \multirow{6}{*}{ 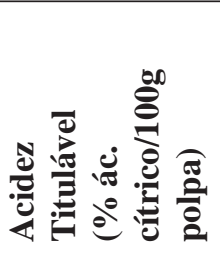 } & Zero & $0,06 \mathrm{Aa}$ & $0,09 \mathrm{Aa}$ & $0,08 \mathrm{Aa}$ & $0,09 \mathrm{Aa}$ & $0,09 \mathrm{Aa}$ & $0,07 \mathrm{Aa}$ \\
\hline & Um & 0,06 Аа & $0,08 \mathrm{Aa}$ & 0,09 Аа & $0,10 \mathrm{Aa}$ & 0,08 Aa & $0,07 \mathrm{Aa}$ \\
\hline & Dois & 0,06 Aa & 0,08 Aa & 0,09 Aa & 0,10 Aa & 0,09 Aa & $0,08 \mathrm{Aa}$ \\
\hline & Três & 0,06 Aa & $0,08 \mathrm{Aa}$ & 0,05 Aa & $0,12 \mathrm{Aa}$ & $0,08 \mathrm{Aa}$ & $0,06 \mathrm{Aa}$ \\
\hline & Quatro & 0,06 Аа & $0,08 \mathrm{Aa}$ & 0,08 Аа & 0,09 Аа & 0,08 Аа & $0,07 \mathrm{Aa}$ \\
\hline & DMS & 0,08 & & & & & \\
\hline \multirow{6}{*}{ 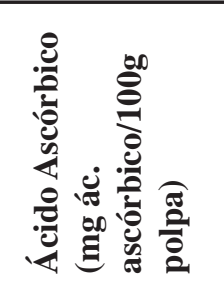 } & Zero & $40,2 \mathrm{Ab}$ & 32,6 Аа & $40,5 \mathrm{Ab}$ & 33,8 Aa & $40,0 \mathrm{Bb}$ & $48,3 \mathrm{Bc}$ \\
\hline & Um & $40,2 \mathrm{Ab}$ & 34,0 Аа & $38,2 \mathrm{Ab}$ & 33,2 Аа & 39,9 Bb & $49,3 \mathrm{Bc}$ \\
\hline & Dois & $40,2 \mathrm{Ac}$ & $28,0 \mathrm{Aa}$ & $36,2 \mathrm{Ab}$ & $37,5 \mathrm{Ab}$ & $40,7 \mathrm{Bbc}$ & $41,2 \mathrm{Bc}$ \\
\hline & Três & $40,2 \mathrm{Ab}$ & 33,6 Аа & 33,3 Аа & 36,3 Аa & 36,0 Aa & 31,3 Аa \\
\hline & Quatro & 40,2 Ac & 30,2 Аа & $35,2 \mathrm{Ab}$ & $36,5 \mathrm{Ab}$ & $35,0 \mathrm{Ab}$ & $35,6 \mathrm{Ab}$ \\
\hline & DMS & 3.9 & & & & & \\
\hline
\end{tabular}

* Médias seguidas por letras distintas, maiúsculas na coluna e minúsculas na linha, diferem entre si, pelo teste de Tukey, a $5 \%$ de probabilidade.

DMS, diferença mínima significativa. 


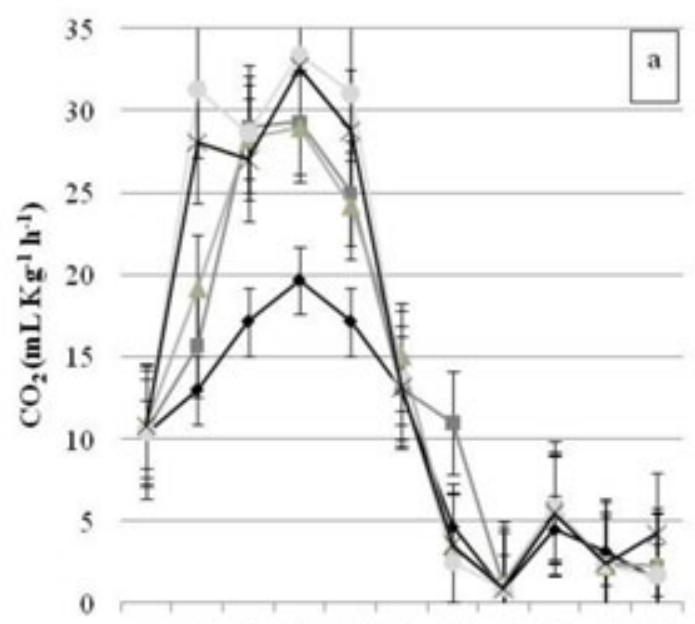

$A D$ ih 4 h 8 h $12 \mathrm{~h} 2 \mathrm{~d} 3 \mathrm{~d} 4 \mathrm{~d} 5 \mathrm{~d} 6 \mathrm{~d} 7 \mathrm{~d}$

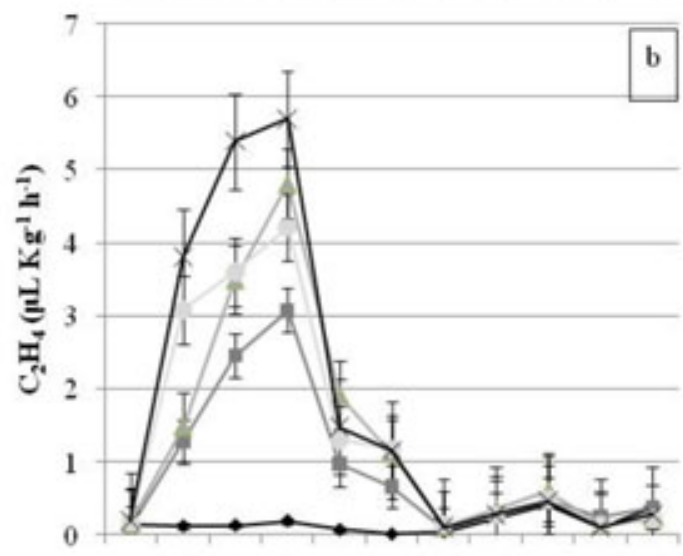

AD 1h th 8 h 12h 2d 3d 4d 5 d 6 d $7 \mathrm{~d}$

Periodo de avaliaç̃o

zero $-\mathrm{m}-\mathrm{um} \rightarrow$ dois - très $\nrightarrow$ quatro
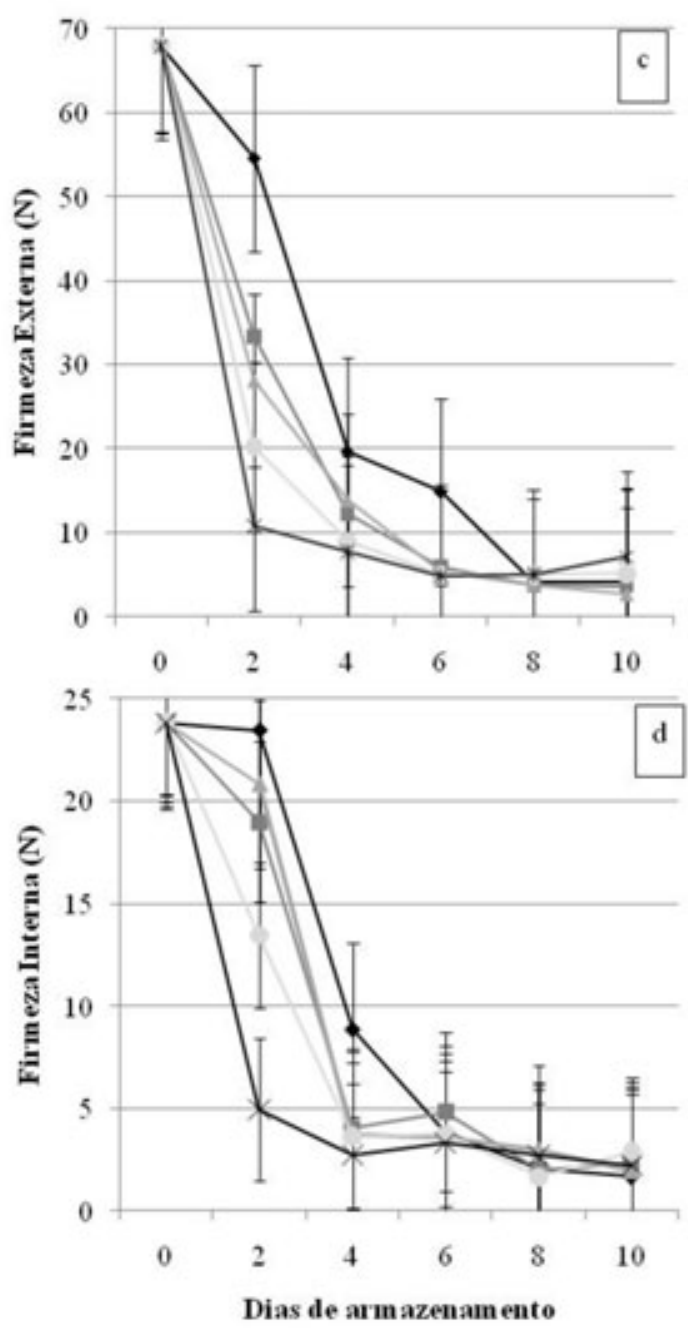

zero - in-um $\rightarrow$-dois - très $\rightarrow$ quatro

FIGURA 1 - Firmeza externa (a) e interna (b), atividade respiratória $\left(\mathrm{CO}_{2}\right)(\mathrm{c})$ e produção de etileno $\left(\mathrm{C}_{2} \mathrm{H}_{4}\right)$ (d) de mamões 'Golden' submetidos ao dano mecânico do tipo corte e armazenados a $22^{\circ} \mathrm{C}$ e $85 \pm 5 \%$ UR por 10 dias. *AD= antes do dano, h= horas após a aplicação do dano, d= dias após o dano. As barras verticais representam o erro-padrão da média.

\section{CONCLUSÃO}

O número de dano mecânico do tipo corte interferiu nos principais atributos de qualidade e na fisiologia pós-colheita do mamão 'Golden', sendo que quanto maior o número de cortes, menor a qualidade dos frutos e maiores as perdas pós-colheita.

\section{AGRADECIMENTO}

Ao CNPq, pela bolsa de iniciação científica do primeiro autor

\section{REFERÊNCIAS}

BALBINO, J. M. de S. Colheita, pós-colheita e fisiologia do amadurecimento do mamão. In: MARTINS, D. dos S.; COSTA, A. de F. S. da. A cultura do mamoeiro: tecnologias de produção. Vitória: Incaper, 2003. cap. 13, p. 403-440. 
BARATA-SOARES, A.D.; GÓMEZ, M.L.P.A.; MESQUITA, C.H.; LAJOLO, F.M. Ascorbic acid biosynthesis: a precursor study on plants. Brazilian Journal of Plant Physiology, Londrina, v.16, n.3, p.147-154, 2004. Disponível em: <http://www.scielo.br/scielo. php?pid=S1677-04202004000300004\&script $=$ sci abstract>. Acesso em: 24 jun. 2009. DOI: 10.1590/ S1677-04202004000300004

BRAGA, L.R. Características químicas e físicas de mamões do grupo 'Solo' submetidos a diferentes injúrias mecânicas. 2004. 46 f. Dissertação (Mestrado em Fitotecnia) - Curso de Pós-Graduação em Fitotecnia, Universidade Federal de Viçosa, Viçosa, 2004.

CARVALHO, C.R.L.; MANTOVANI, D.M.B.; CARVALHO, P.R.N.; MORAES, R.M.M. Análises químicas de alimentos. Campinas: ITAL, 1990. $121 \mathrm{p}$.

DURIGAN, M.F.B.; MATTIUZ, B.H. Efeito de injúrias mecânicas na qualidade de abobrinhas armazenadas em condições ambientes. Horticultura Brasileira, Brasília, v.25 n.2, p. 291-295. 2007. Disponível em: <www.scielo.br/pdf/hb/v25n2/31. pdf $>$. Acesso em: 12 jul. 2009. DOI: 10.1590/S010205362007000200032

DURIGAN, M.F.B.; MATTIUZ, B.H.; DURIGAN, J.F. Efeito de injúrias mecânicas na qualidade pós-colheita de lima-ácida 'Tahiti' armazenada sob condições ambientes. Revista Brasileira de Fruticultura, Jaboticabal, v.27, n.3, p.369-372, 2005. Disponível em: <http://www.scielo.br/pdf/rbf/ v27n3/27776.pdf $>$ Acesso em: 23 jul. 2009. DOI: 10.1590/S0100-29452005000300008

FAO. Disponível em: <http://faostat.fao.org/ site/567>. Acesso em: 20 fev. 2011.

GIANNONI, J.A.; LIMA, L.C.; CHITARRA, M.I.F.; VILAS BOAS, E.V. Armazenamento de pêssegos 'Premier' sob refrigeração e atmosfera modificada. In: CONGRESSO BRASILEIRO DE FRUTICULTURA, 14., 1996, Curitiba. Resumos... Londrina: SBF, 1996. v.14, p.380.
GODOY DE, A.E.; JACOMINO, A.P.; PEREIRA, E.C.C.; GUTIERREZ, A. S.D.; VIEIRA, C.E.M.; FORATO, L. A. Injúrias mecânicas e seus efeitos na qualidade de mamões Golden. Revista Brasileira de Fruticultura, Jaboticabal, v. 32, n. 3, p. 682-691, 2010. Disponível em: <http://www.scielo. br/scielo.php?pid=S0100-29452010005000086>. Acesso em: 29 jul. 2010. DOI: 10.1590/S010029452010005000086

JAENSCH, L.E. Biophysical and biochemical aspects of bruising in potato tubers (Solanum tuberosum L.). 1996. Thesis (PhD) - The Flinders University of South Australia, Adelaide, 1996.

KAYS, S.J. Postharvest physiology of perishable plant products. New York: Van Nostrand Reinhold, 1991. $532 \mathrm{p}$.

KASAT, G.F.; MATTIUZ, B.H.; OGASSAVARA, F.O.; BIANCO, M.S.; MORGADO, C.M.A.; CUNHA JUNIOR, L.C. Injúria mecânica e seus efeitos em pêssego 'Aurora-1'. Revista Brasileira de Fruticultura, Jaboticabal, v.29, n.2, p. 318-322, 2007. Disponível em: <http://www.scielo.br/scielo. php?script $=$ sci_arttext $\&$ pid $=$ S0100 $>$ Acesso em: 21 jul. 2009. DOI: 10.1590/S0100-29452007000200025

MARIN, S.L.; GOMES, J.A.; ALVES, F.L. Introdução, avaliação e seleção do mamoeiro cv. Improved Solo Line 72/12 no Estado do Espírito Santo. Vitória: EMCAPA, 1989. 13p. (Documentos, 59)

MATTIUZ, B.H.; DURIGAN, J.F. Efeito de injúrias mecânicas na firmeza e coloração de goiabas das cultivares Paluma e Pedro Sato. Revista Brasileira de Fruticultura, Jaboticabal, v.23, n.2, p.277-281, 2001. Disponível em: <http://www.scielo.br/scielo. php?script=sci_arttext\&pid> Acesso em: 12 jun. 2009. DOI: 10.1590/S0100-29452001000200015

MOHSENIN, N.N. Physical properties of plant and animal materials: structure, physical characteristics and mechanical properties. $2^{\text {nd }}$ ed. New York: Gordon and Breach, 1986. 891 p. 
MORETTI, C. L. Danos mecânicos. In: FOLGATTI, M. I. da; SILVEIRA; MATSUURA, F. C. A. U. Mamão pós-colheita. Brasília: Embrapa Informação Tecnológica, 2002. 59 p. (Frutas do Brasil, 21).

MORETTI, C.L.; SARGENT, S.A.; HUBER, D.J.; CALBO, A.G.; PUSCHMANN, R. Chemical composition and physical properties of pericarp, locule, and placental tissues of tomatoes with internal bruising. Journal of the American Society for Horticultural Science, Alexandria, v.123, n.4, p.656-660. 1998. Disponível em: <http://apps.isiknowledge.com/ full_record.do?product $=$ WOS\&search_mode $=$ Gen eralSearch\&qid=7\&SID=2DIOb1Lh145EaJapMCj \&page $=1 \&$ doc $=1>$. Acesso em: 30 jul. 2009

PAULL, R. E. Pineapple and papaya, In: SEYMOUR, G. B.; TAYLOR, J. E.; TUCKER, G.A. Biochemistry of fruit ripening. London: Chapman \& Hall, 1993. cap. 10, p. 291-323.

PAULL, R.E.; CHEN, N.J. Postharvest variation in cell wall degrading enzymes of papaya (Carica papaya L.) during fruit ripening. Plant Physiology, New York, v. 72, p. 382-385, 1983.
PURVIS, A. C. The role of adaptive enzymes in carbohydrates oxidation by stressed and senescing plant tissues. HortScience, Alexandria, v.32, n.7, p.1165-1168, 1997.

SMIRNOFF, N. The function and metabolism of ascorbic acid in plants. Annals of Botany, New York, v.78, n.6, p.661-669, 1996. Disponível em: $<$ http://aob.oxfordjournals.org/cgi/content/abstract/78/6/661>. Acesso em: 18 jul. 2009

SMIRNOFF, N.; CONKLIN, P.; LOEWS, F.A. Biosynthesis of ascorbic acid in plants: a renaissance. Annual Review of Plant Physiology and Plant Molecular Biology, Palo Alto, v.52, p.437-467, 2001. Disponível em: <http://arjournals.annualreviews. org/doi/abs/10.1146\%2Fannurev.arplant.52.1.437>. Acesso em: 21 ago. 2009. DOI: 10.1146/annurev. arplant.52.1.437 